\title{
OS LIMITES DA NOÇÃO DE TIPOGRAFIA UNIVERSAL: UMA REFLEXÃO A PARTIR DA DESCONSTRUÇÃO
}

Alberto Cipiniuk, Dr

Pontifícia Universidade Católica do Rio de Janeiro (PUC-Rio)

cipiniuk@puc-rio.br

Wilson Silva Prata, doutorando

Pontifícia Universidade Católica do Rio de Janeiro (PUC-Rio)

wilsonprata@gmail.com

Resumo: Conforme propõe Jacques Derrida pensar a desconstrução permite, dentre outras coisas, demonstrar o dogmatismo que há em toda prática e em todo discurso hegemônico. $O$ presente trabalho procura mostrar como podemos entender a proposta de Herbert Bayer, que defende a noção de uma tipografia universal, a partir da perspectiva da desconstrução. Para tal, primeiramente há um breve delineamento das motivações e ações que possibilitaram o surgimento da Bauhaus, os valores partilhados pelos agentes de tal instituição e que foram utilizados como diretrizes por Bayer para o desenvolvimento da tipografia Universal. Posteriormente são explanados algumas das noções propostas pelo filósofo Jacques Derrida que nos auxiliam a entender os limites da proposição de uma tipografia universal. Por fim essas conclusões são estendidas demonstrando-se a impossibilidade de se estabelecer significados a priori independente das noções, práticas e mecanismos inerentes a toda produção de sentido.

Palavras-chave: Bauhaus, Desconstrução, Tipografia

\begin{abstract}
To think the deconstruction as proposed by Jacques Derrida, allow us, among other things, to demonstrate the dogmatism that permeates every practice and every hegemonic discourse. This paper aims to analyze Herbert Bayer's proposal, who defended the notion of a universal typography, from the deconstruction perspective. To do so, first there is a brief outline of the motivations and actions that made possible the emergence of the Bauhaus, the values shared by the agents of that institution and the ones that were used as guidelines by Bayer for the development of his typography Universal. Following this, some of the notions proposed by the philosopher Jacques Derrida are explained they help us to understand the limits of the proposition of a universal typography. Finally these conclusions are extended demonstrating the impossibility of establishing a priori meanings independent of the notions, practices and meaning inherent to any meaning production.
\end{abstract}


Keywords: Bauhaus, desconstruction, typography.

\section{INTRODUÇÃO}

O surgimento da Bauhaus é celebrado como um marco fundamental para o campo do design. A partir dessa instituição muitos dos cânones do campo foram aperfeiçoados e legitimados, vários deles em vigência até hoje. Obviamente que por mais que a história seja resultado das dinâmicas sociais, são os agentes que concretizam a mudança e ressignificações das práticas por meio de ações individuais, em situações variadas, estas invariavelmente sociais. Assim, o estudo das escolhas feitas pelos agentes dominantes em determinado contexto, isto é, o estudo das ações dos indivíduos que se destacam em um dado campo social, como o campo do design, auxiliam a entender as sobre-determinações da estrutura e também a autonomia que os agentes possuem frente a essas determinações.

Nesse sentido, o sujeito não é mero suporte, efeito ou consequência das estruturas que o excedem, mas também não é senhor absoluto de seu destino. Desse entendimento, abre-se a possibilidade de uma compreensão mais aprofundada das contradições, das coerções e resistências que ocorrem na interação entre sujeitos e sistemas, que absolutamente, não são sistemas fechados.

Ante essa perspectiva epistemológica, conforme postulada por Jacques Derrida a desconstrução se apresenta como um lugar para pensar, para observar e identificar o dogmatismo de todo e qualquer sistema estruturante e estruturado, de suas menores partes, seus agente, até o todo social. O termo desconstrução foi tomado da arquitetura e apresentado por Derrida pela primeira vez na obra Gramatologia, que ao realizar a "decomposição de uma estrutura vigente" salienta que essas ações não devem ser entendida como uma liquidação ou destruição do sistema hegemônico de pensamento, mas como um ato de resistência à tirania inerente a esse tipo de estrutura. ${ }^{1}$ A desconstrução permite assim, identificar as polaridades hierárquicas como as que, por exemplo, ocorrem no pensamento ocidental, ou seja, as dicotomias dentro/fora; corpo/mente; fala/escrita; presença/ausência; natureza/cultura; forma/sentido; etc. Através do "descentramento" do sentido validado, pode-se tanto demonstrar as arbitrariedades necessárias para essa validação como também indicar e desenvolver novas possibilidades de sentido. Assim, a desconstrução não se apresenta como um conceito, pois em si, não aponta uma nova direção, não é um supra-critério para pensar as desigualdades nem um método que pode indistintamente ser aplicado. A desconstrução pode ser melhor entendida como uma estratégia para o pensar.

Tratando-se particularmente do campo do design, os pesquisadores Lupton e Miller fazem uma primeira aproximação da noção de desconstrução com os cânones do campo na obra Design, Writing, Research (1999). Segundo esses autores, Derrida descreve desconstrução como um modo de questionar através e a respeito de tecnologias, instituições sociais e metáforas de representação. Convenções sociais tais como a linguagem, materiais e ferramentas, a grid e os meios que estabelecem vias de sentido. A noção de desconstrução se presta então, a expor os dilemas existentes em

1 PEDROSO JR, Neurivaldo Campos. Jacques Derrida e a Desconstrução: uma Introdução. In: Revista Encontros de Vista, quinta edição. JAN - JUN 2010. 
qualquer texto, sendo texto entendido dentro da lógica derridiana como toda manifestação discursiva presente na escritura, ${ }^{2}$ ainda, segundo o autor, não há nada fora do texto. Esse entendimento rejeita a abordagem de que um significado último pode ser extraído, ou descoberto, de uma obra ou de uma ideia. Pois na escritura não existe estrutura atômica, já que nada existe enquanto tal, apenas nas relações, que tampouco são estanque.

Essa perspectiva será utilizada para a análise da proposta da Bauhaus, mais especificamente de Herbert Bayer, de que seria possível o desenvolvimento de um tipo universal, ou seja, uma tipografia que possa ser universalmente funcional, legível e sem significado determinado a priori. Como o entendimento das ações do sujeito só podem ser estabelecidas a partir de um contexto circunscrito, para essa análise se mostra necessário um breve delineamento histórico da formação do campo e dos valores em voga socialmente naquele período e na instituição na qual esse sujeito se encontrava inserido, no caso, a Bauhaus. A partir disso, pode-se tentar pensar esses valores a partir da dicotomia e da arbitrariedade que carregam em si, para então identificar sua validade e alguns do limites epistemológicos do campo e propor novas possibilidades para o tipo universal.

\section{A CONSOLIDAÇÃO DA BAUHAUS E DO CAMPO DO DESIGN}

Historicamente, o campo do design se estabelece no momento em que o capitalismo já estava consolidado. A ascensão desse sistema produtivo iniciou-se em 1789, e no início do século XX se confirma dominante não só como força produtiva mas também como força social, ou seja, como forma de organização social. Dessa maneira, capitalismo, industrialização e progresso, apesar de serem coisas distintas, eram entendidos praticamente como sinônimos. Por fim, o capitalismo acabou determinando não apenas a instância econômica mas também a agenda política dos países em que era implementado pois "o argumento da industrialização como forma única para se atingir a ideia de progresso foi seu grande trabalho político". ${ }^{3}$

Uma das formas de difusão das ideias, benefícios, valores e ideologia capitalista eram as exposições internacionais como, por exemplo, a Grande Exposição de 1851. A Alemanha após a unificação feita por Bismarck, procurou reestruturar e fortalecer seu mercado interno incorporando as novas soluções produtivas e realizando as mudanças econômicas, laborais e pedagógicas necessária para a implantação desse modelo. Um dos resultados desses esforços foi a criação do Werkbund, uma espécie de associação profissional que reunia artistas, artesãos, arquitetos e designers. Em razão dos seus conflitos e divergências, tanto os internos quanto os externos, o Werkbund trouxe à tona três questões relevantes para o design moderno: i) apresentou, pela primeira vez, toda a complexidade e contradição do design, ii) demonstrou que sem a presença da indústria, não havia possibilidade de design, iii) pautou as questões de gosto, ideologia e estilo do design ao ancorar este em uma teoria da pura visualidade, em um proto-

2 Para Derrida, "Tudo aquilo que... manifestava tendência e conseguia finalmente reunir-se sobre o nome de linguagem começa a deixar-se deportar ou pelo menos resumir sobre o nome de escritura" (DERRIDA, 1973, p. 8).

3 SOUZA, Pedro Luiz Pereira de. Notas para uma história do design. 2.a edição. Rio de Janeiro: 2AB, 2000. 
racionalismo e na renovação do classicismo. Estas questões estão presentes ou renovadas ao longo do desenvolvimento do design desde então. ${ }^{4}$

O Werkbund foi criado com o intuito de fortalecer o mercado interno alemão frente a industrialização, pois segundo os governantes, era pertinente uma instituição social específica dedicada ao desenvolvimento de produtos que levasse em conta as capacidades e limitações da máquina. ${ }^{5}$ Assim o design, agora pejado de sua dimensão moderna, foi eleito como o caminho legítimo para a superação dos problemas advindos da industrialização. Foi preciso então desenvolver uma teoria da pura visualidade baseada no pensamento e ideário dos neoclássicos alemães, que afirmavam a autonomia da arte em relação a realidade, ou seja, do ideal em relação ao natural. A partir de tais noções que vão se desdobrando e se estabelecendo a discussão e os critérios do design moderno, tais como: a importância da forma e da técnica, o desprezo pelo ornamento e a noção de que forma segue função. ${ }^{6}$

Essa noção ignora os conflitos, os interesses e as forças envolvidas nas relações sociais de produção industrial. Entretanto, pouco, ou nada, há de romântico no papel que o design desempenha dentro da sociedade industrial. Uma das principais evidências do surgimento do design como sendo muito mais uma força regulatória do que uma instância poética de resistência ao modelo opressor da indústria é justamente o fato de que o design se estabelece primeiramente como uma proposta de ensino, antes mesmo de ser prática social, ou seja, o design industrial surge primeiro como discurso. Não obstante, esse era um discurso que clamava por um apelo à ordem, à racionalidade e ao método, dogmatismo puro, em uma instância. ${ }^{7}$

A Primeira Guerra mundial implicara em um atraso do projeto nacional alemão, somente em 1923 alguma estabilidade foi conseguida. Até então a Alemanha passava por um período pessimista na arte e na sociedade, as reparações de guerra precisavam ser pagas e o país passou da monarquia à república. Em 1919 surge a Bauhaus, cujo o corpo docente era composto por membros do Werkbund. Em seu primeiro ano, a Bauhaus foi estabelecida na cidade de Weimar e ao longo de 22 anos teve papel fundamental na formação da teoria do design. Mesmo após seu fechamento, que ocorreu em 1933, com a escola agora baseada em Berlim, continuou como forte influência no campo do Design pois sua ideologia se propagou através dos professores e alunos da escola, que imigraram e/ou continuaram exercendo o papel de professores e designers, dentre eles Wassily Kandisky, Paul Klee e Walter Gropius. Apesar de vários autores circunscreverem os esforços iniciais dessa prática ${ }^{8}$, o surgimento da escola pode ser visto como o primeiro capítulo da história do design no século XX. Uma de suas principais propostas e contribuições da escola foi pensar o design de forma teórica e, supostamente, autoconsciente, entretanto o foco se detinha nas recentes teorias da visão e nas propriedades do olhar - tido como autônomo de expressão e livre de determinismos e ideologias -, o que ajudou a construir e engrenar a hostilidade relacionada à linguagem verbal que se tornou comum no ensino do Design pós-guerra.

4 SOUZA, Pedro Luiz Pereira de, op. cit., 2000. p. 17-19.

5 ARGAN, Giulio Carlo, op. cit., 2010, p. 616.

6 SOUZA, Pedro Luiz Pereira de, op. cit., 2000, p. 27-29

7 Ibid., p. 10.

8 Para mais detalhes ver Objetos de Desejo, de Andrian Forty e Desenho Industrial de John Heskett. 
Sua principal herança foi a tentativa de identificar uma linguagem da visão, fazendo uso de experimentos tais como a aplicação das leis da Gestalt em suas peças. A teoria da Gestalt sustenta que o cérebro organiza espontaneamente dados sensíveis em padrões simples, propõe que ver é um processo de ordenar. Contudo, ao se privilegiar estruturas perceptivas, acaba-se por desencorajar reflexões sobre as estruturas sociais e o quanto estas determinam as própria estruturas reflexivas. ${ }^{9}$

Como reflexo das ideias dominantes de seu próprio tempo, o curso de Design da Bauhaus procurava eliminar todas as particularidades do objeto (fosse ele um projeto gráfico ou de produto), em favor da descoberta de verdades fundamentais, com o resgate e uso das formas elementares através de uma hipotética gramática visual básica. ${ }^{10}$ Tentava-se sistematicamente procurar as formas mais puras e mais simples para o desenvolvimento de produtos, galgados na lógica e na razão, e assim tornar o design universal. Com isso, o curso assumiu proporções míticas segundo seus pares. A fim de estudar esses fenômenos e seus desdobramentos de forma mais objetiva, a proposta desse artigo é esmiuçar um exemplo, de uma iniciativa específica dentro do campo, para a melhor compreensão desse problemática. Dentre os projetos desenvolvidos na Bauhaus, um dos que mais representavam os ideais da escola era o desenvolvimento de famílias tipográficas, um dos melhores exemplos dessa produção foi o Universal Type de Herbert Bayer.

Dentre as propostas dos designers modernistas da Bauhaus, destacava-se a intenção de desenvolver uma nova forma de pensar a função do ambiente visual. Para isso, era necessário uma quebra com os padrões então vigentes, pois de acordo com esses designers, estes padrões eram usados para refletir e reforçar uma sociedade hierárquica, além de servirem para encobrir a decadência, falsidade e exploração dessa sociedade. $O$ meio para se realizar tal quebra seria baseando-se nas leis da razão - que acreditavam esses profissionais, serem universais - distantes da cultura tradicional. ${ }^{11}$

Herbert Bayer foi um dos designers que abarcou essa crença em seus projetos. Ele trabalhou na Bauhaus entre 1921 e 1923 e teve um papel importante na confecção de uma nova tipografia que refletisse tais valores. Para isso, Bayer fez uso de tipos sem serifas, linhas grossas e grids sistematizados, o que possibilitou o desenvolvimento de uma fonte que no entendimento de seu criador e de seus pares era "lógica e limpa", com uma geometria "pura", livre de convenções sociais, ancorada na racionalidade e funcionalidade da escrita. Bayer procurava desvendar e revelar as bases formais das letras ocidentais, removendo todos os excessos e "estilos culturais supérfluos" que vieram ser popularizados pela economia de manufatura pós-industrial. Ao remover o ornamento, e toda forma de excesso visual, ele também reforçava um dos ideais da Bauhaus, que era unir o artista à indústria, para com isso desenvolver produtos acessíveis e essenciais.

9 MILLS, Mike, O Universal Type de Herbert Bayer em seus contextos históricos, in.: LUPTON, Ellen e MILLER, J. Abbot (org.). ABC da Bauhaus. Cosac Naify. Tradução André Stolarskis. São Paulo, 2008.

10 Os teóricos da Bauhaus acreditavam que as formas mais básicas eram o triângulo, o quadrado o círculo. Esses elementos possuiriam uma correlação universal com determinadas cores, o amarelo, o vermelho e o azul. Essa composição (triângulo amarelo, quadrado vermelho e círculo azul), tornou-se símbolo da Bauhaus e sua metodologia.

11 MILLS, op. cit., 2008 


\section{A IDEOLOGIA DA BAUHAUS ANTE O PENSAMENTO DE DERRIDA}

A noção de pura visualidade carregava em seu cerne aquilo que Derrida se refere como uma "violência da verdade", uma estrutura sacrificial que assim se apresenta por ignorar outras partes do discurso; nesse caso específico, não apenas todo e qualquer ornamento como também os valores que estes possuíam até então e que poderiam vir a ter. Por estar ancorada na pura visualidade, à maneira positivista, a "violência da verdade" do tipo universal se apresenta como um fato em si, imanente a própria forma. Disso pode-se perceber que o problema aqui apresentado não se caracteriza por uma simples questão de estilo, como poderia parecer a deliberação entre a presença ou ausência de ornamentos, visto que essa escolha é mais profunda que apenas a materialidade do objeto. $O$ que a primeira vista se mostra como uma escolha calcada na racionalidade e em aspectos produtivos, encobre uma ideologia específica, ou seja, uma visão política de como o mundo deve ser. Dessa maneira as superfícies limpas e proporcionais do tipo universal concretizam materialmente um ideal de beleza e justiça, que se justificam tautologicamente, é belo porque é justo, não engana nem dissimula como fazem os ornamentos de produtos que segregam os homens em classes, ricos e pobres, súditos e nobres. Por essa mesma razão, o que é belo, é justo; e por ser justo, é bom.

Essa lógica obedece à tradição ocidental que defende que decidir o que é verdadeiro é análogo a decidir o que é justo, há então uma paridade entre ciência e política, mais exatamente, ciência e ética. As noções sobre esses dois conceitos procedem de uma mesma perspectiva e igualmente se submetem à problemática da legitimação dos agentes e dos discursos. Quem está legitimado para decidir o que é justo (ética/política) e quem está legitimado para decidir o que é verdadeiro (ciência), obedecem a mesma lei civil: determinada categoria de cidadãos devem desempenhar determinado tipo de ação. Com o fim da metafísica, a sustentação do discurso como forma de legitimação leva ao conceito de conhecimento do criador, que entende que conhecer é ser capaz de criar ou produzir aquilo que se conhece ${ }^{12}$, o que é o caso de Bayer e da Bauhaus. Esse conceito determina duas categorias, o povo e a ciência. Ao povo cabe as noções de justiça e à ciência a noção de verdadeiro. Esse fórmula narrativa possui pretensão de universalidade e para sua legitimação exige a destituição da diferença entre o que é injusto daquilo que é falso em prol do uno da verdade. ${ }^{13}$

Cada uma dessas categorias vai possuir um discurso distinto, mas correlato ao outro, no processo de legitimação do saber, um será mais político e o outro mais filosófico. Assim, o estado, que pode ser lido como a civilização, tem como papel colocar o sujeito no caminho correto. Através da política, busca-se legitimar o saber como um direito ético, a humanidade é como um herói da liberdade. O segundo discurso entende que o que legitima as ações da ciência é o "natural movimento do progresso", sendo "natural" aqui tanto entendido como movimento espontâneo,

12 Para uma discussão detalhada do argumento do conhecimento do criador e sua influência no campo do design, ver: CIPINIUK, Alberto; HEINRICH, Fabiana Oliveira; PRATA, Wilson Silva; "O argumento do conhecimento do criador e a metodologia projetual no campo do design", p. 320-328. In: Anais do 110

Congresso Brasileiro de Pesquisa e Desenvolvimento em Design [Blucher Design Proceedings, v. 1, $n$. 4]. São Paulo: Blucher, 2014. ISSN 2318-6968, DOI 10.5151/designpro-ped-00985

13 LYOTTARD, Jean-François. A Condição Pós-Moderna. Tradução: Paulo César de Souza. Rio de Janeiro: Livraria José Olympio Editora, 1979. 
quanto como único sentido possível, pois o não-progresso ou o regresso são abominações.

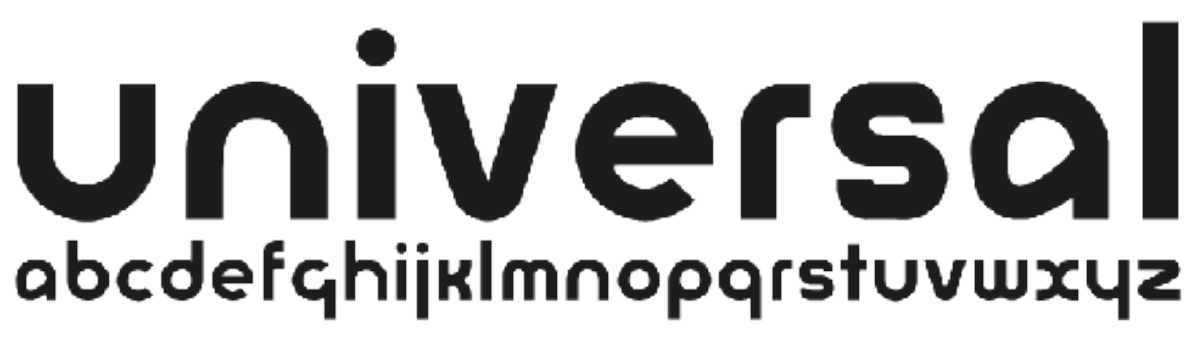

Figura 01 - Tipografia Universal de Herbert Bayer.

Fonte: http://nataliebooth.wordpress.com/2011/10/20/the-bauhaus-movement/

Com isso, pode-se entender mais claramente como a Bauhaus e Bayer acabavam por legitimar o programa político de sua época, mesmo tendo críticas ao modo como esse era implementado. Ao argumentar, por exemplo, que o tipo Universal possuía uma linguagem visual superior, pois a cultura é artificial, já a razão e a ciência são puras ${ }^{14}$, Bayer demonstrava o seu alinhamento, consciente ou inconsciente, com as ideias de progresso que justificaram a proposta industrial capitalista. Além disso, essa forma de entender a cultura reforça a polarização logocêntrica que Derrida aponta como inerente e latente ao pensamento ocidental, no caso, a dicotomia fica entre natureza versus cultura, sendo a cultura artificial por ter sido criada pelo homem, restando ao natural o lugar onde leis imutáveis encontram-se estabelecidas. Nessa perspectiva, cabe a ciência o papel de identificação e compreensão da lógica das leis que regem a natureza.

Entretanto, as estratégias do design não são absolutos universais; em verdade, geram, exploram e refletem convenções culturais. A cultura não se apresenta sempre da mesma maneira, isso porque ela é algo que se produz, circula e se consome na história social, trata-se de uma ação social coletiva e, como tal, é processual e cambiante. Da mesma maneira, é equivocada a noção de que existe um aspecto imutável, uma essência da cultura, e que esse aspecto se perde quando um objeto produzido por uma cultura é produzido com influências, posto em circulação ou consumido de modo distinto do modo como é feito "em sua origem". Essas práticas e objetos não se perdem, na verdade se transformam ao serem inseridos em novas relações sociais e simbólicas, algumas vezes, essas incorporações e ressignificações passam a ser constituintes do próprio objeto não sendo vistas, mesmo pelo produtor, como um perda de identidade, como no caso do artesanato que sofre pequenas mudanças para melhor ser usado como instrumento de decoração ou ainda quando se utilizam ferramentas e processos industriais para a confecção desses objetos. ${ }^{15}$

Os resultados da prática social do design não apenas geram, exploram e refletem convenções sociais, como também, de acordo com o pensamento derridiano, demonstram que é impossível construir um texto sem que este já esteja mergulhado na gramofonia, na referencialidade intrínseca à sua manifestação. Estruturar uma tipografia que seja limpa de qualquer significado, limpa de qualquer rastro, é um

14 MILLS, op. cit., 2008. p. 46.

15 CANCLINI, Néstor Garcia. Diferente, desiguais e desconectados. Tradução: Luiz Sérgio Henriques. Rio de Janeiro: Editora UFRJ, 2005. p. 41-42. 
desejo já frustrado, pois o significado é determinado a todo momento na cultura e pela cultura, isto é, nas práticas relacionadas à produção, circulação e consumo dos aspectos sociais que dão significação à vida. Isso demonstra a impossibilidade de que apenas na produção, resolva-se esse "problema", como também revela que à produção do design não se realiza em uma tabula rasa, por agentes neutros, apartados da sociedade. Como todos os agentes sociais, os designers são um sendo no continuo que é a escritura.

Derrida entende essa angústia de tentar determinar na produção o sentido mais correto e mais exato de algo como um "mal de arquivo", noção que pode ser estendida às inquietações, no âmbito das manifestações e percepções visuais, que motivavam os trabalhos da Bauhaus e de Bayer. Esclarecendo, mal de arquivo é "(...) procurar o arquivo onde ele se esconde. (...) um desejo irreprimível de retorno à origem, uma dor da pátria, uma saudade de casa, uma nostalgia do retorno ao lugar mais arcaico do começo absoluto." 16 Trazendo a questão do mal de arquivo para o objeto de estudo isso se traduz em dois pontos: i) na ânsia de procurar sistematicamente as formas mais puras e mais simples para o desenvolvimento de produtos galgados na lógica e na razão e com isso eliminar os particulares e tornar o design universal; ii) reforçando o papel do agente, visto que os arquivos não podem ser acessado por todos, somente alguns possuem o direito de acessá-los, no caso, somente os designers poderiam propor tal solução. Esse desejo de origem, de apreensão de presença, jamais irá chegar, pois há sempre um adiamento da verdade do sentido, isso é inerente a todo e qualquer rastro. O sucesso de Bayer foi, se muito, um sucesso momentâneo pois a parti dele o que há é outra indicação, outra possibilidade de sentido, outra promessa que jamais há de se cumprir.

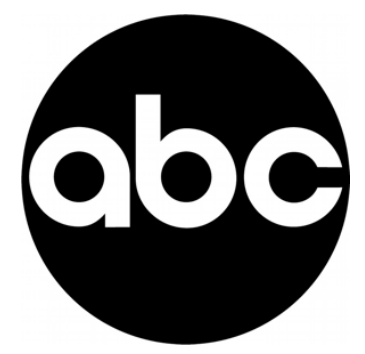

Figura 02 - Marca da rede de televisão ABC. Desenvolvida por Paul Rand, faz uso de uma tipografia baseada na Universal de Herbert Bayer.

Fonte: http://img2.wikia.nocookie.net/_cb20100815064324/logopedia/images/5/56/ABC_logo.svg

Esse adiamento do sentido ocorre porque, no entendimento de Derrida, a escritura não é estanque, e sim dinâmica. Bayer procurou uma tipografia limpa dos significados estabelecidos. Contudo, ao ser incorporada socialmente e ser utilizada nas identidades de grandes corporações (Figura 2), isto é, ao participar das instâncias de circulação e consumo, essa mesma tipografia, e demais tipografias que partilhavam os mesmos valores e configurações formais, o tipo desenhado por Bayer acabou sendo apropriado pelos interesses particulares desses grupos e não mais os de seus produtores (Figura 3). Não se trata necessariamente de uma "riqueza domada", como 
define Barthes apud. Mills ${ }^{17}$, pois, conforme já demonstrado, o sentido de dada representação não é determinado na produção, logo, não se trata de uma suposta distorção do significado real, ideal, determinado pelo criador, mas do próprio processo como toda e qualquer representação se manifesta e ganha sentido na cultura. A universalidade que Bayer alcançou era na verdade um entendimento tópico do que se entendia por universal, produto de regras construídas culturalmente e de seu momento histórico. Aqueles elementos que antes pareciam possuir valores e indicações de serem universais, no momento seguinte já se encontravam carregados de significados completamente opostos ao que Bayer intencionava.

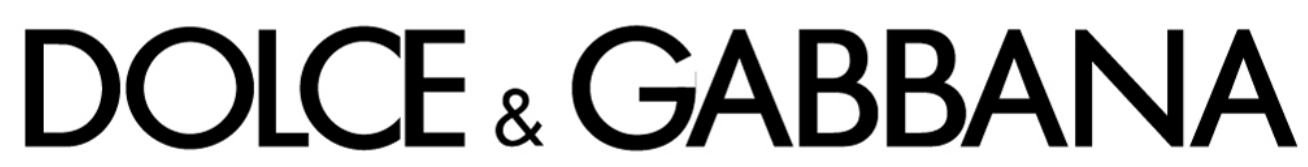

Figura 03 - Marca da grife de moda Dolce \& Gabbana. Que utiliza uma família tipográfica moderna, baseada na tipografia Futura, desenvolvida por Paul Renner que, assim como a Universal de Herbert Bayer, é representativa dos valores estéticos e ideológicos da Bauhaus.

Fonte: http://www.vectorfans.com/wp-content/uploads/2013/08/Dolce-and-Gabbana-Logo-Vector.jpg

\section{CONCLUSÃO}

Derrida reforça o aspecto polissêmico do rastro ante ao idealismo monossêmico que há no entendimento de uma verdade universal, apartada das práticas sociais e da história, tal como a defesa da noção de pura visualidade. Pode-se perceber então que o significado de uma tipografia, ou de qualquer produto, é sempre resultado de uma prática social, não se encontra portanto preso à sua representação formal. Este significado é continuamente recriado por pessoas e instituições, apropriações e reapropriações que em determinados momentos, e de formas muitas vezes alheias à vontade ou consciência de quem as criou, favorecem certos rastros em detrimento de outros. Esses rastros podem, no momento seguinte, inverter toda lógica e intencionalidade daquele que se entende como autor.

A busca por uma tipografia racional, sem elementos supérfluos, embasados em um grid e em com valores estéticos universais, procura preservar o sentido do texto, através de uma manifestação invisível, onde seria possível que a ideia original do autor se manifestasse naturalmente. Todavia, não apenas a escrita habita na fala como ela também transforma a gramática, a fonética e consequentemente sua forma de registro. A estrutura da página, espaços, pontuações, serifas e bordas, caixas altas ou baixas, esses e outros elementos, tanto possibilitam que um texto possa ser lido, como também abrem brechas no discurso. Não há como abraçar toda a gama de sentidos que podem ser construídos e reconstruídos através das práticas de uso daquele texto. Jorge Luis Borges, que construiu sua obra justamente na apropriação e na cópia, práticas tidas como limitantes e limitadoras, para demonstrar magistralmente a impossibilidade de reproduzir o sentido original de uma obra, no caso dos contos Funes, o memorioso; Pierre Menard, Autor do Quixote; e mesmo na história do 
pequeno parágrafo Del rigor em la ciência. Seu trabalho também serve para ilustrar e questionar o quanto se perde ao abraçar o dogmatismo de apenas um entendimento, quando se destacam A casa de Astérion e Três versões de Judas.

Os apontamentos aqui apresentados não buscam destituir a relevância e a importância de desenvolver uma tipografia adequada a uma necessidade. $O$ trabalho de Bayer foi projetar uma tipografia representativa de seu tempo, que fora pensada de acordo com os valores que eram caros a ele e à instituição a qual se filiava. Contudo, certos trabalhos não se encerram com o fim de determinadas tarefas. Assim como a responsabilidade começa a declinar quando se começa a ser dogmático e esquemático, ao ceder a tentação do cálculo, desprezam-se as nuances, as possibilidades de desdobramento. Os escritos de Derrida nos ajudam a entender que certas problematizações são impossíveis de serem resolvidas durante a sua concepção, independente dos esforços desprendidos é impossível na instância de produção controlar todos os resultados; Derrida alude a isso ao apontar o adiamanto da verdade que há em todo rastro. Ainda quanto a desconstrução, revela também que toda produção de sentido, todo processo de ordenação, carrega em si o arbitrário e o dogmático, "sempre se pode dizer, a respeito da desconstrução, que ela acontece e inevitavelmente acontece porque os discursos já trazem na estrutura interna de suas respectivas construções as suas desconstrução". ${ }^{18}$

Se entendermos que existem não apenas respostas erradas mas também perguntas erradas, pode-se então concluir que uma tipografia universal fracassa não porque esse projeto não conseguiu ser instrumento de uma sociedade mais igualitária, mas sim, por se considerar que é possível instituir um consumo mais igualitário e livre de qualquer pressuposto somente através da tipografia. Qualquer coisa se dá sempre na relação, e as relações sociais são dinâmicas. Cada uma delas submetidas a uma série de outras relações, sendo que seus termos nunca se mostram totalmente. 0 aparecimento "enquanto tal" de cada uma dessas etapas - produção, circulação e consumo; coletivo e privado; particular e universal; concreto e abstrato, etc. - é algo sempre, e ao mesmo tempo, prometido e adiado, que só pode ser percebido nas relações, jamais como referência apenas a si, sob o risco de perder sua conexão com o concreto. São entendimento que não podem ser apropriados apenas diferidos, no duplo sentido do termo "diferir", que significa tanto diferenciar quanto adiar, postergar. São representações sociais que não se constituem enquanto tal, são sempre um sendo. Deste modo, o papel do design no consumo e na diminuição das desigualdades é um questionamento que trespassa o design mas que também o transcende, pois trata-se de uma questão política, relaciona-se portanto àquilo que diz respeito ao todo, à coletividade, à cidade e aos cidadãos que nela habitam, que se resolve portanto, na política e através da política.

18 Duque-Estrada, Paulo Cesar. Derrida e o pensamento da desconstrução: o redimensionamento do sujeito. In.: Cadernos IHU Ideais. Ano 8, n.o 143. São Leopoldo/RS, 2010. 


\section{REFERÊNCIAS}

ARGAN, Giulio Carlo. A arte moderna na Europa: de Hogarth a Picasso. São Paulo: Companhia das letras, (1983) 2010.

CANCLINI, Néstor García. Diferente, desiguais e desconectados. Tradução: Luiz Sérgio Henriques. Rio de Janeiro: Editora UFRJ, 2005.

CIPINIUK, Alberto. Design: o livro dos porquês - O campo do design compreendido como produção social. Rio de Janeiro: Editora da PUC-Rio, Editora Reflexão, 2014. No prelo.

CIPINIUK, Alberto; HEINRICH, Fabiana Oliveira; PRATA, Wilson Silva; "O argumento do conhecimento do criador e a metodologia projetual no campo do design", p. 320-328 . In: Anais do 110 Congresso Brasileiro de Pesquisa e Desenvolvimento em Design [Blucher Design Proceedings, v. 1, n. 4]. São Paulo: Blucher, 2014. ISSN 2318-6968, DOI 10.5151/designpro-ped-00985

DERRIDA, Jacques. Eating Well, or the calculation of the subject: an interview with Jacques Derrida. In.: Who Comes After the Subject? eds. Cadava, Connor, \& Nancy. New York: Routledge, 1991, p 96-119.

DERRIDA. Jacques. Gramatologia, São Paulo: Ed. Perspectiva. 1973.

DUQUE-ESTRADA, Paulo Cesar. Jamais se renuncia ao Arquivo: notas sobre "Mal de arquivo" de Jacques Derrida. In.: Revista Natureza Humana, vol. 12, n.o 2. São Paulo, 2010.

DUQUE-ESTRADA, Paulo Cesar. Derrida e o pensamento da desconstrução: o redimensionamento do sujeito. In.: Cadernos IHU Ideais. Ano 8, n.o 143. São Leopoldo/RS, 2010.

FORTY, Adrian. Objetos de Desejo. Tradução: Pedro Maia Soares. Cameron Books, 1986. São Paulo: Cosac Naify, (1986) 2007. 352 p.

GAY, Peter. Modernismo: o fascínio da heresia, de Baudelaire a Beckett e mais um pouco. Tradução: Denise Bottmann. São Paulo: Companhia das Letras, 2009.

LUPTON, Ellen e MILLER, J. Abbot (org.). ABC da Bauhaus. Cosac Naify. Tradução André Stolarskis. São Paulo, 2008.

LUPTON, Ellen e MILLER, J. Abbot. Deconstruction and Graphic Design. In.: Design writing research: writing on graphic design. Phaïdon, 1999.

LYOTTARD, Jean-François. A Condição Pós-Moderna. Tradução: Paulo César de Souza. Rio de Janeiro: Livraria José Olympo Editora, 1979.

PEDROSO JR, Neurivaldo Campos. Jacques Derrida e a Desconstrução: uma Introdução. In.: Revista Encontros de Vista, quinta edição. JAN - JUN 2010.

SOUZA, Pedro Luiz Pereira de. Notas para uma história do design. 2.a edição. Rio de Janeiro: 2AB, 2000. 